\title{
The comparison of causal relationships of job stress between Thai immigrant employees with and without rearing their aging parents
}

\author{
Chonticha Kaewanuchit \\ Department of Applied Sciences, Faculty of Science and Technology, \\ Phranakhon Si Ayutthaya Rajabhat University, \\ Phra Nakhon Si Ayutthaya, Thailand, and \\ Yothin Sawangdee \\ Institute of Population and Social Research, Mahidol University, \\ Nakhon Pathom, Thailand
}

\begin{abstract}
Purpose - The occupational stress is a disadvantage resulting in mental health illnesses that have been found when looking at those migrants who were young adults and migrated to work in the urban areas, leaving behind their aging parents to live alone at home. The purpose of this paper is to compare the causal relationships of job stress between Thai immigrant employees with and without rearing aging parents.

Design/methodology/approach - The research was a cross-sectional survey. The sample for this study included 600 Thai immigrant employees (300 cases per group) in 2016. Measures included individual characteristics, working conditions, and a Thai Job Content Questionnaire (Thai-JCQ) on related job stress. The model was verified using a path model by Mplus software.

Findings - The distance traveled between the house and the workplace, wages, working conditions had a direct effect on job stress. Working conditions among Thai immigrants employees with rearing aging parents had the most direct effect on job stress with a standardized regression weight of $0.552(p$-value $<0.05)$ as well as working conditions among their without rearing aging parents had the most direct effect on job stress with a standardized regression weight of -0.292 .
\end{abstract}

Originality/value - This research demonstrated that working conditions were an important factor.

Keywords Job stress, Thai immigrant employees, Causal relationship, Aging parents

Paper type Research paper

\section{Introduction}

The survey conducted by WHO on employee population of about 1,900 million people regarding worldwide risk of problems related to their work showed that there are 160 million employees experiencing illness. There are 8 percent of them who have occupational stress, which is the same as Thai employees who suffer stress and anxiety the most (32.24 percent) and were in working age of 26-30 years in 2014[1]. The occupational stress is a disadvantage

(C) Chonticha Kaewanuchit and Yothin Sawangdee. Published in the Journal of Health Research. Published by Emerald Publishing Limited. This article is published under the Creative Commons Attribution (CC BY 4.0) licence. Anyone may reproduce, distribute, translate and create derivative works of this article (for both commercial \& non-commercial purposes), subject to full attribution to the original publication and authors. The full terms of this licence may be seen at http://creativecommons. org/licences/by/4.0/legalcode

This research project was funded by the National Research Council of Thailand, Thailand. The authors would like to thank participants for this research and the native English editor who edited English language in this research before submission.
Comparison of causal relationship of job stress

Received 16 November 2017 Accepted 9 February 2018 
JHR

32,3

resulting in the loss of working potential and in mental health illnesses[1]. The development of Thai society focuses on industrial society under globalization, which has become the turning point of society, with economic changes in Thailand including Thai immigrant employees[2] under AEC policies[3]. A survey disclosed that Thai immigrant employees still tended to work in the same regions, rather than in different regions $[4,5]$.

Some studies explained that migrants who were employees need to adapt themselves to new environment while leaving their aging parents to live alone in rural areas. When their aging parents have illnesses, it leads to anxiety to them[6]. Several studies found that poor working conditions, job insecurity, poor occupation, great distances, and inconvenient transportation were associated with occupational stress, anxiety, and depression[7-10]. For example, some paper in China concluded that time period, wages, family support, housing conditions, age, and job characteristics were related to mental health[11], and job demands (such as, carrying heavy loads, an awkward posture, and psychological demands), decision latitude, (such as, skill variety and job control) and support (such as, supervisory control and the safety climate) were all linked to both mental and physical health issues[12, 13-18], high job responsibility[19], or different occupational characteristics, such as job stress among Thai farm worker[20], poor wages associated with job stress and pressure[21] including great distance[17, 21].

In contradiction, some immigrant employees had conflicts between work and rearing their family (i.e. children, spouse, and/or aging parent). This became a psychosocial problem and led to poor mental health[22]. For example, male migrants who were separated from family always suffered from mental health, fear, anxiety, and depression [23]. These are also found among females who were working as maids[24]. That is to say, job conditions were important factor that contributed to mental health[17]. It is important and necessary to compare the causal relationships and job stress among employees between those who were supporting their aging parents to the other group who were not. As a result, operational definitions consisted of, first, working conditions, means questions about exploitation, job characteristics, working environment, and workloads, which have effected job stress; second, supporting aging parents who are older than 60 years old and live in their original province; third, wages represent the total incomes from both part-time and full-time jobs in Thai baht/month (1 baht $\approx \$ 35)$; fourth, employees are rural-urban migrants who work in Bangkok $(n=352$ cases) and Nonthaburi provinces ( $n=248$ cases), whose original provinces are neither of these provinces, fifth, job stress is pressure, occupational stress, burnout, job control, job-confliction-related to poor mental health and job potency, and finally, the distance traveled between their home town and the workplace in kilometers.

\section{Materials and methods}

\section{Sample and recruitment}

A cross-sectional study was conducted in 2016-2017. The respondents are migrants who work in Bangkok and Nonthaburi, their age is between 20 and over, and are able to literate. The sample design included two groups: who were supporting their aging parents in Nonthaburi ( $n=100$ cases) and Bangkok ( $n=200$ cases), and who did not look after and take care of their aging parents in Nonthaburi ( $n=148$ cases) and Bangkok ( $n=152$ cases). Each group had 300 cases because of calculated formula by Mplus guideline. The sampling technique is stratified random sampling, which divided the population into stratum and took a random sampling from the strata. Finally, Muang and Bang Kruai district in Nonthaburi and Bang Phlat and Ratchathewi district in Bangkok were selected. The respondents were screened under criteria: self-identified as either supported their aging parents or not. A total of 600 participants were recruited to answer self-report questionnaire. 


\section{Instruments}

Measures forming three parts (67 questions) were considered: individual characteristic (eight questions), working conditions while supporting aging parents or not, and Thai Job Content Questionnaire (Thai-JCQ). The Thai-JCQ were assessed[25] by using items modified from the demand-control-support model[27]. For example, individual characteristics composed of sex, education, marital status, age, occupation, wages, and distance from home town. Besides, the location of workplace and working conditions were also included. While their perceived potential of an employer to affect the working conditions is a perception of employer control, the response options ranged from "none" (1), "less" (2), "more" (3) "most" (4). The Cronbach's $\alpha$ coefficient of working conditions among Thai immigrant with rearing aging parents and without rearing aging parents was 0.80 and 0.85 , respectively. The with/ without supporting aging parents were assessed with applied questions (eight items). The selected items asked about their travels to look after their aging parents, care giving for them, their direct responsibility for their parents, etc., and how supporting their aging parents affected their job stress. The Cronbach's $\alpha$ coefficient in supporting or not supporting their aging parents was 0.75 and 0.79 , respectively. All items used the four-point Likert format. The job stress was measured with the Thai-JCQ[25] by using items modified from the demand-control-support model[27]. They are job control, psychological job demands, physical job, job security, social support, and hazard at work. In total, 51 of the items in the scale used a four-point Likert format with response options ranging from "strongly disagree" (1) through to "strongly agree" (4). The total Thai-JCQ was calculated by summing the items $(\alpha=0.84$ and 0.79$)$ with Thai immigrant employees who were supporting their aging parents and those who were not. Values for the scale ranged from $>80$ percent, with the highest values indicating the highest job stress among participants who were supporting their aging parents. In contrast, values for the scale ranged from $<60$ percent, with the lesser values indicating less job stress among participants who were not supporting their aging parents. The verification of the data accuracy was passed in the terms of content and construct validity by five professors. The reliability was examined by Cronbach's $\alpha$ coefficient from SPSS program version 20 . This questionnaire's reliability was 0.82 .

\section{Ethical consideration}

Before the data collection was undertaken, this research was accepted by the Human Ethics Committees (social sciences) from Mahidol University, Thailand, and the code was COA. No. 2016/254.0507, while the Thai Clinical Trials Registry code was TCTR 20160712002.

\section{Data collection}

Data were collected by the researchers and assistant researchers. Self-administered surveys were conducted in public places (e.g. park, road) and the participants' homes. The principal investigator described the entire questionnaire to the assistance researchers. If the participants had difficulties with understanding the questions, the assistant researchers provided further explanations. All participants took approximately 60 minutes to complete the questionnaire. After that, all of the completed questionnaires from the participants were put in a sealed container.

\section{Data analysis}

We adjusted all the statistical analyses for the stratified sampling design of this study. We summarized the sample by using percentages for the data. We compared distance, wages, working conditions, support for aging parents, and the job stress between those participants supporting their aging parents and those who did not by using a path model for the
Comparison of causal relationship of job stress 
JHR

32,3

260

continuous variables. We presented maximum likelihood estimates, a path analysis of variance, analysis of $R^{2}$, and measurement of the goodness of fit of the path model by Mplus version 5.2[26] and we considered $p$-values less than 0.01 and 0.05 statistically significant. The rule for the test of the path model fit for a population of over 250 population and observed variables $<12$ was acceptable, with a $\chi^{2}$ and degree of freedom $\neq 0, p$-value $>0.05$, comparative fit index $>0.95$, root-mean-square error of approximation $<0.07$, standardized root-mean-square residual $<0.05[26]$.

\section{Results}

Participant personnel and job stresses are presented in Tables I and II. Then, the model fit of the causal relationship was deemed acceptable, as shown in Table III. In this causal relationship among Thai immigrant employees who either supported their aging parents or did not, the addition of various factors increased the explanation of variance in job stress by 53.1 percent ( $p$-value $<0.01$ ), and 43.9 percent ( $p$-value $<0.01$ ), respectively (Table III). This model showed a mediating effect of causal factor (i.e. with/without rearing aging parents) on the relationship between working conditions, wages, distance, and job stress (Figure 1).

\section{Discussion}

This highlights that the empirical study is the first and outstanding research finding of Thailand because Thai immigrant employees who looked after their aging parents are less stress than immigrant employees without rearing their aging parents due to blood bonding in Thai society. Therefore, employers should set up activities (i.e. exercise, entertainment, and relaxation) to reduce job stress. In addition, it can increase the labor productivity.

Similar to other immigrant employees, these immigrant employees who looked after left-behind family members (such as, aging parents, spouses, and children) experienced relatively high levels of stress[24, 28]. Working conditions were most consistently associated with the job stress among both those Thai immigrant employees with rearing aging parents as well as those employees without rearing aging parents. Nevertheless, working conditions among employees without rearing aging parents should be verified in the future because of the negative effects on the job stress. In addition, the wages and distance variables had a direct effect on the job stress in both groups. However, it could be considered that both variables still had less effect than the working conditions, and had little association with job stress.

The research on the associations between working conditions, mental health problems (e.g. stress), and health among immigrant employees remains limited[17, 29-32]. This analysis builds on this study and supports the importance of causal relationships, especially, the path model for understanding and improving public health based on the occupational health of vulnerable immigrant employees. This is among the first attempts to include measures from each variable of the path model in one analysis.

Like other analyses, these results document the association of working conditions, wages, distance, and other variables with the job stress among immigrant employees but these analyses lack the linkage of left-behind family members of immigrant employees. For example, Siriwardhana et al.[24] in a recent analysis described the health impact of migration on their left-behind family members and conducted in-depth interviews. They indicated that the migration of the left-behind family members was perceived to have a negative effect on the overall health, low moods, cheerlessness, anxiety, and depressive symptoms.

The associations found in the analysis reflect other studies of the healthy migrant effects from the Mexican family life survey[33] and the negative effects of international migration on the families in Indonesia[34]. In contrast, there was a study reporting occupational stress, 


\begin{tabular}{|c|c|c|c|c|}
\hline \multirow{2}{*}{ General geographic data } & \multicolumn{2}{|c|}{ Province } & \multirow[b]{2}{*}{ Total } & \multirow{4}{*}{$\begin{array}{r}\text { Comparison } \\
\text { of causal } \\
\text { relationship of } \\
\text { job stress }\end{array}$} \\
\hline & Bangkok & Nonthaburi & & \\
\hline Location of workplace & $66.6(n=200)$ & $33.4(n=100)$ & $100.0(n=300)$ & \\
\hline Age (year old): $20-29$ & $6.0(n=18)$ & $4.0(n=12)$ & $10.0(n=30)$ & \\
\hline $30-39$ & $35.0(n=105)$ & $15.0(n=45)$ & $50.0(n=150)$ & \\
\hline $40-49$ & $18.7(n=56)$ & $8.0(n=24)$ & $26.7(n=80)$ & \\
\hline $50-59$ & $7.0(n=21)$ & $6.3(n=19)$ & $13.3(n=40)$ & 261 \\
\hline Sex: Female & $50.0(n=150)$ & $23.3(n=70)$ & $73.3(n=220)$ & \\
\hline Male & $16.7(n=50)$ & $10.0(n=30)$ & $26.7(n=80)$ & \\
\hline Education: Primary school & $5.0(n=15)$ & $3.0(n=9)$ & $8.0(n=24)$ & \\
\hline Secondary school & $25.4(n=76)$ & $15.0(n=45)$ & $40.4(n=121)$ & \\
\hline Bachelor Degree & $35.3(n=106)$ & $15.3(n=46)$ & $50.6(n=152)$ & \\
\hline Master Degree & $1.0(n=3)$ & - & $1.0(n=3)$ & \\
\hline Marital status: Single & $56.0(n=168)$ & $10.7(n=32)$ & $66.7(n=200)$ & \\
\hline Widowed & $10.3(n=31)$ & $20.0(n=60)$ & $30.3(n=91)$ & \\
\hline Marriage & $0.3(n=1)$ & $2.7(n=8)$ & $3.0(n=9)$ & \\
\hline Occupation: Civil servant & $6.0(n=18)$ & $4.0(n=12)$ & $10.0(n=30)$ & \\
\hline Permanent employee & $41.7(n=125)$ & $15.0(n=45)$ & $56.7(n=170)$ & \\
\hline Temporary employee & $19.0(n=57)$ & $14.3(n=43)$ & $33.3(n=100)$ & \\
\hline Wages (baht/month): $\leqslant 5,000$ & $3.0(n=9)$ & $2.0(n=6)$ & $5.0(n=15)$ & \\
\hline $5,001-10,000$ & $10.0(n=30)$ & $2.7(n=8)$ & $12.7(\mathrm{n}=38)$ & \\
\hline $10,001-15,000$ & $23.0(n=69)$ & $10.3(n=31)$ & $33.3(\mathrm{n}=100)$ & \\
\hline $15,001-20,000$ & $20.7(n=62)$ & $9.3(n=28)$ & $30.0(n=90)$ & \\
\hline $20,001-25,000$ & $5.0(n=15)$ & $4.0(n=12)$ & $9.0(n=27)$ & \\
\hline $25,001-30,000$ & $3.0(n=9)$ & $2.0(n=6)$ & $5.0(n=15)$ & \\
\hline $30,001-35,000$ & $2.0(n=6)$ & $3.0(n=9)$ & $5.0(n=15)$ & \\
\hline Distance $(\mathrm{km}): 1-30$ & $2.0(n=6)$ & - & $2.0(n=6)$ & \\
\hline $31-60$ & $5.0(n=15)$ & - & $5.0(n=15)$ & \\
\hline $61-90$ & $5.0(n=15)$ & $5.0(n=15)$ & $10.0(n=30)$ & \\
\hline $91-120$ & $13.0(n=39)$ & $15.0(n=45)$ & $28.0(n=84)$ & \\
\hline $121-150$ & $7.0(n=21)$ & - & $7.0(n=21)$ & \\
\hline $151-180$ & $6.0(n=18)$ & - & $6.0(\mathrm{n}=18)$ & \\
\hline $181-210$ & $6.0(n=18)$ & $4.0(n=12)$ & $10.0(n=30)$ & \\
\hline $211-240$ & - & $4.0(n=12)$ & $4.0(n=12)$ & \\
\hline $241-270$ & $0.3(n=1)$ & $2.7(n=8)$ & $3.0(n=9)$ & \\
\hline $271-300$ & $9.0(n=27)$ & - & $9.0(n=27)$ & \\
\hline $301-330$ & $6.3(n=19)$ & $2.7(n=8)$ & $9.0(n=27)$ & \\
\hline $331-360$ & $3.0(n=9)$ & - & $3.0(n=9)$ & \\
\hline $361-390$ & $2.0(n=6)$ & - & $2.0(n=6)$ & \\
\hline $391-420$ & $2.0(n=6)$ & - & $2.0(n=6)$ & \\
\hline Working condition: None & $17.0(n=51)$ & $3.0(n=9)$ & $20.0(n=60)$ & \\
\hline Less & $15.0(n=45)$ & $5.0(n=15)$ & $20.0(n=60)$ & \\
\hline More & $15.0(n=45)$ & $19.0(n=57)$ & $34.0(n=102)$ & \\
\hline Most & $19.7(n=59)$ & $6.3(n=19)$ & $26.0(n=78)$ & \\
\hline With rearing aging parents: None & - & - & - & \\
\hline Less & $19.3(n=58)$ & $10.7(n=32)$ & $30.0(\mathrm{n}=90)$ & \\
\hline More & $25.0(n=75)$ & $20.0(n=60)$ & $45.0(n=135)$ & Table I. \\
\hline Most & $22.3(n=67)$ & $2.7(n=8)$ & $25.0(n=75)$ & Percentage of general \\
\hline Job stress: Low stress & $1.3(n=4)$ & $4.0(n=12)$ & $5.3(n=16)$ & geographic data \\
\hline Medium stress & $33.7(n=101)$ & $6.3(n=19)$ & $40.0(n=120)$ & $\begin{array}{r}\text { among Tha1 } \\
\text { immigrant employees }\end{array}$ \\
\hline High stress & $31.7(n=95)$ & $23.0(n=69)$ & $54.7(n=164)$ & with rearing their \\
\hline Note: $n=300$ & & & & aging parents \\
\hline
\end{tabular}

mental health, and satisfaction among immigrant in the Canadian multicultural workplace[35]. Moreover, a recent research by Hsich et al.[36] reported on work conditions and health and well-being of Latino hotel housekeepers who were immigrant employees in the USA, especially, in terms of psychological wellness, the time pressure of cleaning rooms quickly, 
Province

Location of workplace

Age (year old): 20-29

30-39

262

40-49

50-59

Sex: Female

Male

Education: Primary school

Secondary school

Bachelor Degree

Master Degree

Marital status: Single

Widowed

Marriage

Occupation: Civil servant

Permanent employee

Temporary employee

Wages (baht/month): $\leqslant 5,000$

$5,001-10,000$

$10,001-15,000$

$15,001-20,000$

$20,001-25,000$

25,001-30,000

$30,001-35,000$

Distance (km): 1-30

31-60

61-90

91-120

$121-150$

$151-180$

$181-210$

211-240

241-270

271-300

301-330

$331-360$

$361-390$

391-420

Working condition: None

Less

More

Most

Without rearing aging parents: None

Table II.

Percentage of general geographic data among Thai immigrant employees without rearing their aging parents
Less

More

Most

Job stress: Low stress

Medium stress

High stress

Note: $n=300$

Bangkok

$66.6(n=200)$

$0.6(n=2)$

$28.3(n=85)$

$18.8(n=56)$

$3.0(n=9)$

$29.0(n=87)$

$21.7(n=65)$

$10.4(n=31)$

$16.7(n=50)$

$23.3(n=70)$

$0.3(n=1)$

$34.0(n=102)$

$3.4(n=10)$

$13.4(n=40)$

$0.3(n=1)$

$24.3(n=73)$

$26.1(n=78)$

$1.0(n=3)$

$1.6(n=5)$

$0.6(n=2)$

$30.0(n=90)$

$16.3(n=49)$

$0.3(n=1)$

$0.6(n=2)$

Nonthaburi Total

$33.4(n=100)$

$2.7(n=8)$

$30.0(n=90)$

$14.6(n=44)$

$2.0(n=6)$

$9.3(n=28)$

$40.0(n=120)$

$12.6(n=38)$

$16.7(n=50)$

$20.0(n=60)$

$23.3(n=70)$

$6.6(n=20)$

$19.3(n=58)$

$3.0(n=9)$

$29.0(n=87)$

$17.3(n=52)$

$5.0(n=15)$

$5.4(n=16)$

$12.4(n=37)$

$16.0(n=48)$

$4.7(n=14)$

$2.7(n=8)$

$3.4(n=10)$

$1.0(n=3)$

$1.0(n=3)$

$3.0(n=9)$

$3.3(n=10)$

$8.0(n=24)$

$2.0(n=6)$

$11.7(n=35)$

$1.0(n=3)$

$3.0(n=9)$

$13.3(n=40)$

$28.3(n=85)$

$14.4(n=43)$

$4.0(n=12)$

$-$

$2.0(n=6)$

$1.0(n=3)$

$1.0(n=3)$

$-$

$33.4(n=100)$

$0.3(n=1)$

$10.0(n=30)$

$17.3(n=52)$

$16.0(n=48)$

$4.0(n=12)$

$15.6(n=47)$

$2.3(n=7)$

$22.4(n=67)$

$24.7(n=74)$

$15.7(n=47)$

$13.1(n=39)$

$20.6(n=62)$ $100.0(n=300)$

$3.3(n=10)$

$58.3(n=175)$

$33.4(n=100)$

$5.0(n=15)$

$38.3(n=115)$

$61.7(n=185)$

$23.0(n=69)$

$33.4(n=100)$

$43.3(n=130)$

$0.3(n=1)$

$57.3(n=172)$

$10.0(n=30)$

$32.7(n=98)$

$3.3(n=10)$

$53.3(n=160)$

$43.4(n=130)$

$6.0(n=18)$

$7.0(n=21)$

$13.0(n=39)$

$46.0(n=138)$

$21.0(n=63)$

$3.0(n=9)$

$4.0(n=12)$

$1.0(n=3)$

$1.0(n=3)$

$3.0(n=9)$

$3.3(n=10)$

$10.0(n=30)$

$2.0(n=6)$

$3.0(n=9)$

$25.0(n=75)$

$1.0(n=3)$

$42.7(n=128)$

$4.0(n=12)$

$2.0(n=6)$

$1.0(n=3)$

$1.0(n=3)$

$33.7(n=101)$

$27.3(n=82)$

$20.0(n=60)$

$19.0(n=57)$

$$
-
$$

$37.3(n=112)$

$30.0(n=90)$

$32.7(n=98)$

$30.3(n=91)$

$45.7(n=137)$

$24.0(n=72)$

and work-related stress stemming from major work-related stress factors. Although the strong associations of working conditions with the job stress and health-related quality of life found in this analysis[36] differ from analyses of this present research, it can be seen that it lacked the linkage of employees supporting or not supporting elderly parents; while this present research 


\begin{tabular}{|c|c|c|c|}
\hline \multirow[b]{2}{*}{ Criteria } & \multicolumn{2}{|c|}{ Value } & \multirow{4}{*}{$\begin{array}{r}\text { Comparison } \\
\text { of causal } \\
\text { relationship of } \\
\text { job stress }\end{array}$} \\
\hline & With rearing aging parents & Without rearing aging parents & \\
\hline$\chi^{2}$ & 0.806 & 1.2 & \\
\hline $\mathrm{df}$ & & & \\
\hline$p$-value & 0.369 & 0.2586 & \\
\hline Comparative fit index & 1.000 & 0.999 & \\
\hline Root-mean-square-error of approximation & 0 & 0.030 & 26 \\
\hline standardized root-mean-square residual & 0.011 & 0.011 & \\
\hline$R^{2}$ (with/without rearing aging parents) & $0.081^{*}$ & $0.276^{*}$ & \\
\hline$R^{2}$ (job stress) & $0.531^{*}$ & $0.439 *$ & rall test of mod \\
\hline Note: $* p$-value $<0.05$ & & & \\
\hline
\end{tabular}

(a)

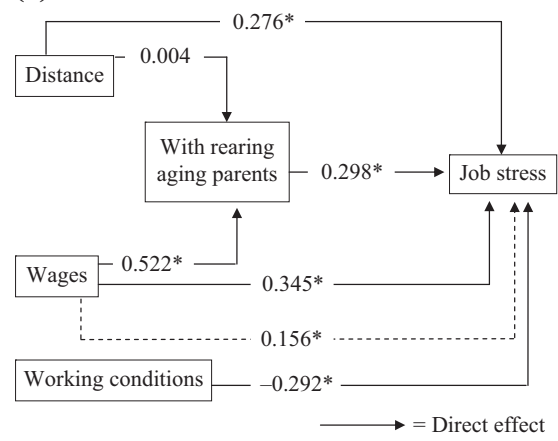

(b)

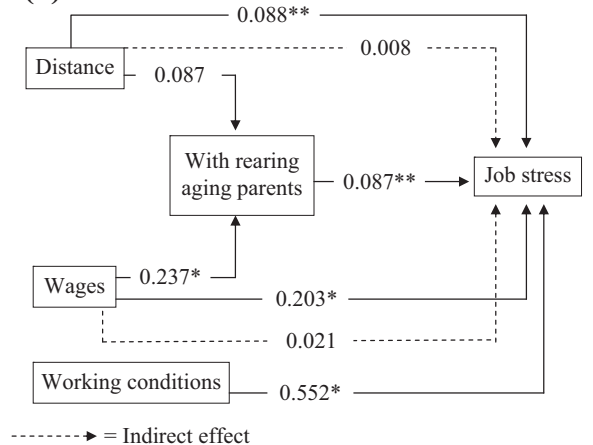

Notes: (a) Without rearing aging parents; (b) with rearing aging parents. ${ }^{*} p$-value $<0.05$; **p $p$-value $<0.01$

attempts to link variables and job stress in this study. Moreover, the public health perspective is based on occupational health, especially on occupational hazards, which are divided into four broad categories, particularly, psychosocial health hazards[21]. Generally, the public health system does not pay sufficient attention to psychosocial health hazards, such as job stress.

There were several limitations in the present study. The limited association of working conditions and job stress having a negative effect among Thai immigrant employees who were not supporting aging parents is surprising. Hsich et al.[36] reported on working conditions which were associated with job stress as did Kaewanuchit and Sawangdee[16]. Working conditions had a direct positive effect on the majority of job stresses. Likewise, this present, and different, study that collected data from amongst Thai immigrant employees without rearing aging parents could reflect the difference between both employees with and without rearing aging parents. It could also indicate that working conditions may be a more important variable than the other variables in the cause of job stress in Thai immigrant employees and other vulnerable employees.

This suggestion should be confirmed to clarify the study limitation in the near future. Thus, the main limitation of this study is that it focused on immigrant employees with rearing and without aging parents. But it also did not study all of the left-behind family members, such as children and spouses. It should have included the other left-behind family members. The final limitation in this study is that its methodology only uses the 
JHR

32,3

path model, which is quantitative analysis to create an understanding about what the real causes are. This recommendation should also have been studied using the qualitative method. Good examples of this are in-depth interviews, focus groups, and observation.

The strengths of this study are that the first path model in both groups explained 53.1 and 43.9 percent of the variance in job stress, respectively. It implied that the model fit of the path model was strongly acceptable. There has only been one report of this type of study attempting to compare the causal relationships of job stress between Thai immigrant employees who do or do not support their aging parents using the path model, which can lead toward guidelines for mental health policy. However, this study has a strong sample design, a large enough sample size, high participation rate, extensive collection of information, and the use of existing job stress measures.

Future research should expand the working conditions' characteristics and job stresses that are examined in depth and using specific details by the qualitative method. Future research should also add the other left-behind family members, such as children and spouses, among immigrant employees. Finally, a longitudinal research is needed to determine the specific structural equation modeling analysis of working conditions and job stress among immigrant employees.

\section{References}

1. Social Communication Center: Department of Mental Health. Ministry of Public Health, Public Health. 2015 [Updated: 2015 Apr 30; cited 2015 Jul 28]. Available from: www.forums.dmh.go.th/ index.php?topic=137965.0;wap2

2. Niyomsilpa S. Change of migration patterns in Asia: towards regional economic integration. In: Punpuing S, Sunpuwan M, editors, Thailand's Population in Transition: a Turning Point for Thai Society, Bangkok: Danetula Printing; 2011: pp. 67-84.

3. Ministry of Social Development and Human Security. The Satiation of Immigrant Employees. Ministry of Social Development and Human Security, Bangkok; 2013.

4. The National Statistical Office. The survey of Thai immigrant population from The National Statistical Office. [Updated: 2014 Jul 30; cited 2014 Aug 30]. Available from: http://social.nesdb. go.th/SocialStat/StatReport_FullScreen.aspx?reportid=83\&template=3R1C\&yeartype=M\& subcatid $=2(2557)$

5. Bureau of Policy and Strategy. Statistical Thailand 2013. Nontaburi: Bureau of Policy and Strategy. Ministry of Public Health, Thailand; 2015.

6. Yodthong D, Seeherunwong A, Kongsuriyanavin W, Au-Yeong AP. Correlation between age, caregiving burden feelings and depressive symptoms in grandparents rearing their grandchildren. Thai J Nursing Council. 2014; 29(1): 108-21.

7. Hiott AE, Grzywacz JG, Davis SW, Quandt SA, Arcury TA. Migrant farmworker stress: mental health implications. J Rural Health. 2008; 24(1): 32-9.

8. Grzwacz JG. Mental health among farmworkers in the Eastern United States. In: Arcury TA, Quandt SA, editors, Latino Farmworkers in the Eastern United States: Health, Safety, and Justice. 2009; Springer, New York, NY, pp. 153-72.

9. Grzywacz JG, Chatterjee AB, Quandt SA, Talton JW, Chen H, Weir M, et al. Depressive symptoms and sleepiness among Latino farmworkers in Eastern North Carolina. J Agromedicine. 2011; 16(4): $251-60$.

10. Georges A, Alterman T, Gabbard S, Grzywacz JG, Shen R, Nakamoto J, et al. Depression, Social factors, and farmworker health care utilization. J Rural Health. 2013; 29(S1): s7-16.

11. Wong DF, Leung G. The functions of social support in the mental health of male and female migrant workers in China. Health Soc Work. 2008; 33(4): 275-85. 
12. Arcury TA, Grzywacz JG, Chen H, Mora DC, Quandt SA. Work organization and health among immigrant women: Latina manual workers in North Carolina. Am J Public Health. 2014; 104(12): 2445-52.

13. Amponsah-Tawiah K, Leka S, Jain A, Hollis D, Cox T. The impact of physical and psychosocial risks on employee well-being and quality of life: the case of the mining industry in Ghana. Safety Sci. 2014; 65(5): 28-35.

14. Dunlavy AC, Rostila M. Health inequalities among workers with a foreign background in Sweden: do working conditions matter?. Int J Environ Res Public Health. 2013; 10(7): 2871-7.

15. Filiz Z. An analysis of the levels of job satisfaction and life satisfaction of the academic staff. Soc Indic Res. 2014; 116(3): 793-808.

16. Kaewanuchit C, Sawangdee Y. A path model of job stress using Thai job content questionnaire (Thai-JCQ) among Thai immigrant employees at the central region of Thailand. Iran J Public Health. 2016; 45(8): 1020-8.

17. Kaewanuchit C, Sawangdee Y. A path analysis of mental health among Thai immigrant employees in Pranakron Si Ayutthaya Province. J Immigr Minor Health. 2016; 18(4): 871-7.

18. Kaewanuchit C, Muntaner C, Isha N. A causal relationship of occupational stress among university employees. Iran J Public Health. 2015; 44(7): 931-8.

19. Levy BS, Wegman DH, Baron SL, Sokas RK. Occupational and Environmental Health: Recognizing and Preventing Disease and Injury. 6th ed., Oxford University Press, Inc., New York, NY; 2011.

20. Kaewanuchit C, Muntaner C, Labonte R, Johnson DA. Stress among Thai farm workers under globalization: a causal model. Pertanika J Soc Sci \& Hum. 2015; 23(1): 169-82.

21. Gatchel RJ, Schultz IZ. Handbook of Occupational Health and Wellness. Spinger Science+Business Media, New York, NY; 2012.

22. Hettige ST, Ekanayake ES, Jayasundere B, Rathnayake A, Figurado P. Understanding Psychosocial Issues Faced by Migrant Workers and Their Families. The Ministry of Foreign Employment Promotion and Welfare, Switzerland; 2012.

23. Letiecq BL, Grzywacz JG, Gray KM, Eudave YM. Depression among Mexican men on the migration frontier: the role of family separation and other structural and situational stressors. J Immigr Minor Health. 2014; 16(6): 1193-200.

24. Siriwardhana C, Wickramage K, Jayaweera K, Adikari A, Weerawarna S, Van Bortel T, et al. Impact of economic labour migration: a qualitative exploration of left-behind family member perspectives in Sri Lanka. J Immigr Minor Health. 2015; 17(3): 885-94.

25. Phakthongsuk P. Construct validity of the Thai version of the job content questionnaire in a large population of heterogeneous occupations. J Med Assoc Thai. 2009; 92(4): 564-72.

26. Hair JE, Black WC, Babin BJ, Anderson RE. Multivariate Data Analysis with Reading. Prentice Hall, Inc, NJ; 2009.

27. Karasek RA. Job demands, job decision latitude, and mental strain: implications for job redesign. Adm Sci Q. 1979; 24(2): 285-308.

28. Perry-Jenkin M, Wadsworth SM. Work and family through time and space: revisiting old themes and charting new directions. In: Peterson GW, Bush KB, editors Handbook of Marriage and the Family. Springer Science + Business Media, New York, NY: 2013; pp. 549-72.

29. Grzywacz JG, Quandt SA, Arucry TA. Immigrant farmworkers' health-related quality of life: an application of the job demands-control model. J Agric Saf Health. 2008; 14(1): 79-92.

30. Swanberg JE, Clouser JM, Westneat S. Work organization and occupational health: perspectives from Latinos employed on crop and horse breeding farms. Am J Ind Med. 2012; 55(8): 714-28.

31. Grzywacz JG, Arcury TA, Marin A, Carrillo L, Coates ML, Burke B, et al. The organization of work: implications for injury and illness among immigrant Latino poultry-processing workers. Arch Environ Occup Health. 2007; 62(1): 19-26. 
32. Grzywacz JG, Arcury TA, Mora D, Anderson AM, Chen H, Rosenbaum DA, et al. Work organization and muculoskeletal health: clinical findings among immigrant Latino worker. J Occup Environ Med. 2012; 54(8): 995-1001.

33. Rubalcava LN, Teruel GM, Thomas D, Godman N. The healthy migrant effect: new finding from the Mexican family life survey. Am J Public Health. 2008; 98(1): 78-84.

34. Hugo G. Effects of international migration on the family of Indonesia. Asian Pac Migr J. 2002; 11(1): 13-46.

35. Pasca R, Wagner SL. Occupational stress, mental health and satisfaction in the Canadian multicultural workplace. Soc Indic Res. 2012; 109(3): 377-93.

36. Hsih YC, Apostolopoulos Y, Sönmez S. Work conditions and health and well-being of Latina hotel housekeepers. J Immigr Minor Health. 2016; 18(3): 568-81.

\section{Corresponding author}

Chonticha Kaewanuchit can be contacted at: sim356@yahoo.com

For instructions on how to order reprints of this article, please visit our website: 